\title{
NUEVOS PATRONES MIGRATORIOS EN LA FRONTERA NORTE: LA EMIGRACIÓN
}

\author{
MARIO MARgulis \\ RODOLFO TUIRÁN \\ El Colegio de México
}

\section{INTRODUCCIÓN}

ESTE ARTículo ESTÁ baSAdo EN los datos provenientes de la encuesta realizada en la ciudad de Reynosa (1980) y en las fuentes censales de diversos municipios de la frontera norte. Se examinan aquí las nuevas modalidades de crecimiento poblacional del decenio 1970-1980 tanto de Reynosa como de las principales ciudades y municipios de la frontera. Estas modalidades difieren notablemente de las observadas en periodos anteriores, sobre todo en el crecimiento social y sus componentes. En las páginas que siguen se presentan los siguientes hallazgos:

a) El crecimiento social en las principales ciudades fronterizas se ha reducido a niveles mínimos o a tasas negativas durante el decenio 1970-1980.

b) En los principales municipios fronterizos se observan, en ese mismo periodo, tasas negativas de crecimiento social.

c) En las zonas rurales de esos municipios de la frontera, las tasas negativas de crecimiento social son muy elevadas, y se remontan -en general- al decenio 1960-1970.

d) La ausencia -casi total- de crecimiento social, no implica la desaparición de la inmigración a las ciudades fronterizas. Hemos 
encontrado que la inmigración ha continuado afluyendo y que ha existido también, durante el último decenio, una emigración importante que compensó y en ocasiones desbordó los aportes inmigratorios.

e) De acuerdo con los datos censales, parece importante la participación de los nativos en esa emigración.

\section{EVOLUCIÓN DE LA POBLACIÓN EN LAS PRINCIPALES CIUDADES DE LA FRONTERA NORTE}

A partir de 1930 se inicia un importante crecimiento en la población de la zona fronteriza norte del país, que se acelera en forma notable en el decenio 1940-1950. La intensa migración fue el principal desencadenante del auge demográfico en ciudades y municipios fronterizos, pero también el elevado crecimiento natural contribuyó a la extraordinaria expansión poblacional.

Los cuadros que siguen ilustran los ritmus y características de este crecimiento. El cuadro 1 permite apreciar la transformación de los poblados existentes en 1930 en importantes ciudades. En sólo 50 años la población se multiplicó; Tijuana pasó -por ejemplo-de 8384 habitantes a 429500 y Reynosa de 4840 en 1930 a 194693 en 1980. ${ }^{1}$ También se observa -en el mismo cuadro- que las tasas anuales de crecimiento fueron muy elevadas hasta 1970 , y que fue superior el incremento proporcional de las ciudades al experimentado por los municipios. En las páginas siguientes profundizaremos sobre este aspecto.

Un análisis por decenio pone de manifiesto que el despegue poblacional, en términos absolutos y relativos, se produjo entre 1940 y 1950; este decenio muestra en las principales ciudades y municipios de la frontera norte las mayores tasas de crecimiento demográfico. Tal expansión está asociada con la puesta en marcha de grandes distritos de riego, con la intensa atracción derivada de la demanda de fuerza de trabajo por parte de los E.U.A., como consecuencia de la guerra y la inmediata postguerra, con los efectos de la reactivación económica norteamericana en las ciudades mexicanas de la frontera, y también con la iniciación de actividades extractivas e industriales en algunos municipios, como Piedras Negras y Reynosa.

1 Entre 1930 y 1980 las principales ciudades fronterizas han crecido a las tasas medias anuales que se mencionan a continuación: Reynosa, $7.67 \%$; Nuevo Laredo, $4.57 \%$; Matamoros, $6.04 \%$; Mexicali, 6.47\%; Tijuana, $8.19 \%$ Entre 1930 y 1980 Ciudad Juárez creció a razón de un $5.38 \%$ anual. 
Cuadro 1. México: Volumen de población y tasas de crecimiento intercensales de las principales ciudades y municipios de la región fronteriza: $1930-1980$

\begin{tabular}{|c|c|c|c|c|c|c|c|c|c|c|c|}
\hline & \multicolumn{6}{|c|}{ Años } & \multirow{2}{*}{\multicolumn{5}{|c|}{ Tasa anual de crecimientoa }} \\
\hline & 1930 & 1940 & 1950 & 1960 & 1970 & 1980 & $1930-40$ & $\begin{array}{r}\text { Tasa } \\
1940-50\end{array}$ & & $\begin{array}{l}\text { nientoa } \\
1960-70\end{array}$ & $1970-80$ \\
\hline \multicolumn{12}{|l|}{ Ciudades: } \\
\hline Reynosa & 4840 & 9412 & 34087 & 74140 & 137383 & 194693 & 7.01 & 13.38 & 8.08 & 6.61 & 3.43 \\
\hline Nvo. Laredo & 21636 & 28872 & 57668 & 92627 & 148867 & 201731 & 2.98 & 6.98 & 4.85 & 5.04 & 2.98 \\
\hline Matamoros & 9733 & 15699 & 45846 & 92327 & 137749 & 188745 & 4.99 & 11.02 & 7.25 & 4.24 & 3.09 \\
\hline Cd. Juárez & 39669 & 48881 & 122566 & 252119 & 407370 & 544496 & 2.15 & 9.38 & 7.48 & 5.10 & 2.82 \\
\hline Mexicali & 14842 & 18775 & 64609 & 174540 & 263498 & 341559 & 2.43 & 12.81 & 10.44 & 4.36 & 2.54 \\
\hline Tijuana & 8384 & 16486 & 59952 & 152374 & 277306 & 429500 & 7.14 & 13.42 & 9.77 & 6.41 & 4.32 \\
\hline Rfo Bravo & 746 & 936 & 4610 & 17500 & 39018 & 55236 & 2.31 & 16.99 & 14.27 & 8.65 & 3.42 \\
\hline \multicolumn{12}{|l|}{ Muntciplos: } \\
\hline \multicolumn{12}{|l|}{ Reynosa y } \\
\hline Río Bravo & 12346 & 23137 & 69428 & 134869 & $222175^{b}$ & $294934^{b}$ & 6.61 & 11.32 & 6.87 & 5.31 & 2.78 \\
\hline $\begin{array}{l}\text { Nvo. Laredo } \\
\text { Matamoros y }\end{array}$ & 23128 & 31502 & 59496 & 96043 & 151253 & 203286 & 3.20 & 6.40 & 4.91 & 4.82 & 2.90 \\
\hline Valle Hermoso & 24955 & 54136 & 128347 & 186027 & 228433 & 287183 & 8.21 & 8.79 & 3.78 & 2.15 & 2.24 \\
\hline Cd. Juárez & 43138 & 55024 & 131308 & 275995 & 424135 & 567365 & 2.51 & 8.86 & 7.71 & 4.51 & 2.83 \\
\hline Mexicali & 29985 & 44399 & 124362 & 281333 & 396324 & 510664 & 4.08 & 10.57 & 8.51 & 3.62 & 2.48 \\
\hline Tijuana & 11271 & 21977 & 65364 & 165690 & 340583 & 461257 & 7.04 & 11.22 & 9.75 & 7.76 & 2.98 \\
\hline
\end{tabular}

Fuente: Censos Generales de Población 1930, 1940, 1950, 1960, 1970 y 1980, Dirección General de Estadística.

Las tassa de crecimiento se obtuvieron a partir de la siguiente fórmula: $\mathrm{Pf}=\mathrm{Po}(\mathrm{i}+\mathrm{r})^{\mathrm{t}}$ donde:

$\mathrm{P}_{\mathrm{f}}=$ Población al final del periodo

$i=$ Tasa de crecimiento

$b^{b}$ La pobiación del munichpio de Reynosa fue de 150786 en 1970 y de 211412 en 1980. La del municipio de Río Bravo: 71389 en 1970 y 83522 en 1980. 
En el cuadro 2 se describe la evolución demográfica -por decenios- de las principales ciudades y municipios fronterizos, y se destaca el papel desempeñado por el crecimiento social. ${ }^{2}$ Este cuadro permite apreciar las tendencias registradas en los componentes del crecimiento poblacional $y$, sobre todo, poner de manifiesto la influencia de los saldos migratorios en el aumento de la población. Puede verse con claridad que, en términos relativos, la migrạción avanza como factor poblacional entre 1930 y 1950; y a partir de ese último año las. tasas comienzan a descender. En el decenio 19501960 , las tasas de crecimiento social superan aún visiblemente - con excepción de Nuevo Laredo- el crecimiento natural. Entre 1960 y 1970 la declinación de las tasas de crecimiento social es evidente en las principales ciudades; sin embargo, en términos absolutos, la migración neta sigue siendo muy importante, pues esas tasas derivan de una población base ya muy incrementada. ${ }^{3}$ En el decenio 19701980 surge de los datos censales que, pese a las expectativas esbozadas en algunos estudios sobre frontera, la migración neta ha descendido bruscamente en términos relativos y absolutos, alcanzando niveles muy bajos en Reynosa y Río Bravo y tasas negativas en Matamoros, Nuevo Laredo, Ciudad Juárez y Mexicali. De tal modo, las principales ciudades de la frontera norte dejan de ser lugares de "fuerte atracción de migrantes" para convertirse en espacios, que desde el punto de vista del crecimiento social, pueden calificarse como de equilibrio" o de "débil expulsión".4 Lo mismo ocurre en los municipios fronterizos, pero en ellos las tasas de crecimiento social ya habian

2 Los cuadros 2 y 3 han sido confeccionados empleando un procedimiento que parte del supuesto que las tasas de crecimiento natural -en este caso en las ciudades y municipios de la frontera- son similares a las registradas a nivel nacional para cada uno de los periodos intercensales. Para abundar en las ventajas e inconvenientes de esta técnica de evaluación del crecimiento social, véase Gustavo Cabrera Acevedo, "Población, migración y fuerza de trabajo", en Migración y Desarrollo, vol. 4, CLACSO; Buenos Aires, 1977, pp. 173-215.

3 Por ejemplo Reynosa tuvo entre 1950 y 1960 una tasa de crecimiento social de aproximadamente $5 \%$ y el saldo neto migratorio estimado para ese periodo fue de 21500 personas. Entre 1960 y 1970, su tasa anual de crecimiento social se redujo a $3.21 \%$, pero el aumento de la población atribuido a migración neta se elevó a unas 26500 personas.

4 De acuerdo con la clasificación que propone G. Cabrera Acevedo, op. cit., p. 183, en el decenio 1960-1970 las principales ciudades fronterizas serían clasificadas como de "fuerte atracción" con excepción de Matamoros y Mexicali que se situarían en la categoría "débil atracción". Para el periodo 1970-1980 las ciudades de Reynosa, Nuevo León, Matamoros y Río Bravo pasarían a la categoría de "equilibrio" mientras que Mexicali y Ciudad Juárez se ubicarían en "débil expulsión" y Tijuana en "débil atracción". 
experimentado un fuerte descenso entre 1960 y 1970 , y reflejaron entre 1970 y 1980 -en general-saldos de crecimiento social negativos. Esto parece indicar un cambio en la intensidad de los flujos migratorios, por lo que la zona fronteriza deja de ser una de las áreas nacionales más dinámicas en cuanto a crecimiento social, para transformarse en un espacio que parece comenzar a expulsar migración hacia las otras regiones. 5

Las tasas de menor crecimiento social observadas en los municipios, en relación con las ciudades principales de los mismos señaladas en el párrafo anterior, se explican sobre todo por la emigración de la población rural. Esto se pone de manifiesto, si se examina el cuadro 3 , que registra el promedio anual de crecimiento de las tasas (total, natural y social) en las áreas rurales de los principales municipios de la frontera. Se puede apreciar que en 1960-1970, hubo tasas de crecimiento social negativo de cierta importancia en las áreas rurales de los municipios principales, con excepción de Tijuana. Entre 1970 y 1980, las tasas de crecimiento social negativo alcanzaron -según el cuadro-a todos los municipios examinados.

Es necesario hacer algunas consideraciones en torno al comportamiento, a primera vista extraño, de las tasas de crecimiento social en las áreas rurales de algunos municipios: nos referimos a Nuevo Laredo, Juárez y Tijuana. Los municipios de Juárez y Nuevo Laredo, muestran grandes fluctuaciones al comparar las tasas en los diversos periodos intercensales, $y$ esto se explica por la escasa proporción de población rural que los caracteriza. Ya que la población rural es de escasa magnitud, las fluctuaciones son en realidad poco trascendentes. ${ }^{6}$

5 En otros municipios fronterizos de los estados de Tamaulipas y Coahuila se registran también tasas medias anuales negativas de crecimiento social entre 1970 y 1980 . Tal el caso de Acuña $(-0.80 \%)$, de Díaz Ordaz $(-3.53 \%)$ y de Miguel Alemán $(-2.59 \%)$. En las cabeceras de estos municipios las tasas fueron también negativas. Una excepción es Piedras Negras, con una tasa positiva de crecimiento social del $2.08 \%$ anual en el municipio y de $1.63 \%$ anual en la ciudad.

6 En 1950 la población rural de Nuevo Laredo era de 1827 habitantes, en 1960 de 3416 , en 1970 de 2386 y en 1980 de 1555 , representando sucesivamente $3.1,3.6,1.6$ y 0.8 por ciento de la población total del municipio. En este caso las fluctuaciones, en las tasas, son en realidad poco importantes. En Ciudad Juárez, la población rural evolucionó de la siguiente forma: 1950, 8742 habitantes; 1960,$23876 ; 1970,16765$; y 198022969 . Los porcentajes sucesivos con respecto a la población total del municipio fueron los siguientes: $6.7,8.6,3.9$ y 4.0 por ciento. En este caso, si bien la urbanización es en 1950 muy elevada, las proporciones y las magnitudes absolutas de la población son superiores a los de Nuevo Laredo, y llama la atención la curiosa evolución de la 
Cuadro 2. México: Tasas anuales de crecimiento total, natural y social de las principales ciudades y municipios de la región fronteriza: 1930-1980 Tasas anuales de crecimiento

\begin{tabular}{|c|c|c|c|c|c|c|c|c|c|c|c|c|c|c|c|}
\hline \multirow{2}{*}{$\begin{array}{l}\text { Ciudades y } \\
\text { Municipios }\end{array}$} & \multirow[b]{2}{*}{ Total } & \multicolumn{2}{|c|}{$1930-1940$} & \multirow[b]{2}{*}{ Total } & \multicolumn{2}{|c|}{$1940-1950$} & \multicolumn{3}{|c|}{$1950-1960$} & \multicolumn{3}{|c|}{$1960-1970$} & \multicolumn{3}{|c|}{$1970-1980$} \\
\hline & & Natural ${ }^{a}$ & Social & & & Social & Total & Natural $^{a}$ & Social & Total & Natural $^{a}$ & Social & Total & Natural $^{a}$ & Social \\
\hline Ciudades: & 7.01 & 1.77 & 5.26 & 13.38 & 2.69 & 10.69 & 8.08 & 3.08 & 5.00 & 6.61 & 3.40 & 3.21 & 3.43 & 3.30 & 0.13 \\
\hline Reynosa & 2.98 & 1.77 & 1.21 & 6.98 & 2.69 & 4.29 & 4.85 & 3.08 & 1.77 & 5.04 & 3.40 & 1.64 & 2.98 & 3.30 & -0.32 \\
\hline Matamoros & 4.99 & 1.77 & 3.22 & 11.02 & 2.69 & 8.33 & 7.25 & 3.08 & 4.17 & 4.24 & 3.40 & 0.84 & 3.09 & $\mathbf{3 . 3 0}$ & -0.21 \\
\hline Ciuđad Juárez & 2.15 & 1.77 & 0.38 & 9.38 & 2.69 & 6.69 & 7.48 & 3.08 & 4.40 & 5.10 & 3.40 & 1.70 & 2.82 & $\mathbf{3 . 3 0}$ & $-0.4 \varepsilon$ \\
\hline Mexicali & 2.43 & 1.77 & 0.66 & 12.81 & 2.69 & 10.12 & 10.44 & 3.08 & 7.36 & 4.36 & 3.40 & 0.96 & 2.54 & 3.30 & -0.76 \\
\hline Tijuana & 7.14 & 1.77 & 5.37 & 13.42 & 2.69 & 10.73 & 9.77 & 3.08 & 6.69 & 6.41 & 3.40 & 3.01 & 4.32 & 3.30 & 1.02 \\
\hline Río Bravo & 2.31 & 1.77 & 0.54 & 16.99 & 2.69 & 14.03 & 14.27 & 3.08 & 11.19 & 8.65 & 3.40 & 5.25 & 3.42 & 3.30 & 0.12 \\
\hline \multicolumn{16}{|l|}{$\begin{array}{l}\text { Municipios: } \\
\text { Reynosa y }\end{array}$} \\
\hline Río Bravo & 6.61 & 1.77 & 4.84 & 11.32 & 2.69 & 8.63 & 6.87 & 3.08 & 3.79 & 5.31 & 3.40 & 1.91 & 2.78 & 3.30 & -0.52 \\
\hline $\begin{array}{l}\text { Nvo. Laredo } \\
\text { Matamoros y }\end{array}$ & 3.20 & 1.77 & 1.43 & 6.40 & 2.69 & 3.71 & 4.91 & 3.08 & 1.83 & 4.82 & 3.40 & 1.42 & 2.90 & 3.30 & $-0.4 c$ \\
\hline Valle Hermoso & 8.21 & 1.77 & 6.44 & 8.79 & 2.69 & 6.10 & 3.78 & 3.08 & 0.70 & 2.15 & $\mathbf{3 . 4 0}$ & -1.25 & 2.24 & 3.30 & -1.06 \\
\hline Ciudad Juárez & 2.51 & 1.77 & 0.74 & 8.86 & 2.69 & 6.17 & 7.71 & 3.08 & 4.63 & 4.51 & 3.40 & 1.11 & 2.83 & 3.30 & -0.47 \\
\hline Mexicali & 4.08 & 1.77 & 2.31 & 10.57 & 2.69 & 7.88 & 8.51 & 3.08 & 5.43 & 3.62 & 3.40 & 0.22 & 2.48 & 3.30 & -0.82 \\
\hline Tijuana & 7.04 & 1.77 & 5.27 & 11.22 & 2.69 & 8.53 & 9.75 & 3.08 & 6.67 & 7.76 & 3.40 & 4.36 & 2.98 & 3.30 & -0.32 \\
\hline
\end{tabular}

Fuente: Cálculos elaborados con base en los datos del cuadro 1.

a E1 "crecimiento natural" es igual a la tasa nacional de cada periodo intercensal. La tasa de crecimiento natural del período 1970-1980 fue calculada con base en los
coultados preliminares del X Censo General de Población y Vivienda, D.G.E. S.P.P. 1980. 
Cuadro 3. Mexico: Evolución de las tasas de crecimiento total, natural y social de los principales municipios fronterizos con exclusion de la ciudad principal: $1930-1980$

\begin{tabular}{|c|c|c|c|c|c|c|c|c|c|c|c|c|c|c|c|}
\hline \multirow{2}{*}{$\begin{array}{l}\text { Municipios } \\
\text { (excepto Cd. } \\
\text { principal) }\end{array}$} & \multicolumn{3}{|c|}{$1930-1940$} & \multicolumn{3}{|c|}{$1940-1950$} & \multicolumn{3}{|c|}{$1950-1960$} & \multicolumn{3}{|c|}{$1960-1970$} & \multicolumn{3}{|c|}{$1970-1980$} \\
\hline & Total & Natural & Social & Total & Natural & Social & Total & Natural & Social & Total & Natural & Socinl & Total & Natural & Social \\
\hline \multicolumn{16}{|l|}{ Reynosa y } \\
\hline Río Bravo & 6.69 & 1.77 & 4.92 & 8.93 & 2.69 & 6.24 & 3.47 & 3.08 & 0.39 & 0.59 & 3.40 & -2.81 & -0.16 & 3.30 & -3.46 \\
\hline $\begin{array}{l}\text { Nuevo Laredo } \\
\text { Matamoros y }\end{array}$ & 5.93 & 1.77 & 4.16 & -3.49 & 2.69 & -6.18 & 6.45 & 3.08 & 3.37 & -3.64 & 3.40 & -7.04 & -4.06 & 3.30 & -7.36 \\
\hline Valle Hermoso & 9.85 & 1.77 & 8.08 & 6.83 & 2.69 & 4.14 & 0.32 & 3.08 & -2.76 & -0.90 & 3.40 & -4.30 & -0.13 & 3.30 & -3.43 \\
\hline Ciudad Juárez & 5.98 & 1.77 & 4.21 & 3.50 & 2.69 & 0.81 & 11.02 & 3.0 & 7.94 & -4.01 & 3.40 & -7.41 & 3.07 & 3.30 & -0.23 \\
\hline Mexica & 5.50 & 1.77 & 3.73 & 8.61 & 2.69 & 5.92 & 5.98 & 3.08 & 2.90 & 2.28 & 3.40 & -1.12 & 2.36 & 3.30 & -0.94 \\
\hline Tijuana & 6.76 & 1.77 & 4.99 & -0.14 & 2.69 & -2.83 & 9.42 & 3.08 & 6.34 & 17.49 & 3.40 & 14.09 & -6.45 & $\mathbf{3 . 3 0}$ & -9.75 \\
\hline
\end{tabular}

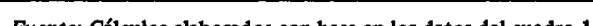

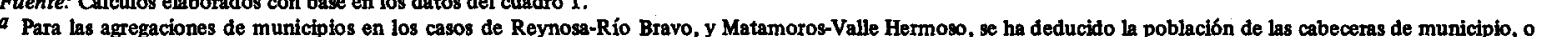
sea, en el primer caso de las chidades de Reynosa y de Río Bravo y en el segundo de las chudades de Matamoros y do Valle Hermoso. 
En el caso de Tijuana llama la atención el comportamiento del promedio de las tasas anuales de crecimiento total y social de su población rural, sobre todo en los últimos tres decenios. En efecto, mientras que en 1950-1960 esas tasas experimentaron una fuerte alza, con $9.42 \%$ de promedio anual en el crecimiento total y $6.34 \%$ anual en el crecimiento social, en 1960-1970, registran -según los censos - un alza desmesurada y absolutamente ajena a los niveles y tendencias observados en los demás municipios fronterizos (véase cuadro 3) con $17.49 \%$ anual de crecimiento total y $14.09 \%$ de crecimiento social. Pero en 1970-1980 ambas tasas se desplomaron, registrándose un crecimiento negativo en la tasa promedio de crecimiento total de $-6.45 \%$ anual y de $-9.75 \%$ anual en el crecimiento social (que también se alejaron de los otros municipios fronterizos).

La explicación de estas fluctuaciones es difícil de encontrar con base, solamente, en los datos censales. Resulta significativa, sin embargo, la presencia en el censo de 1970 de Mesa de Tijuana (calificada como Colonia Agrícola) con 50094 habitantes, mientras que en el censo de 1960 esta localidad sólo figura con 2926 habitantes. En cambio en 1980 no aparece ninguna localidad mayor de 10000 habitantes, con excepción de la ciudad de Tijuana.

Una investigación acerca de esta aparente anomalía nos permitió descubrir que en el Catálogo de Integración Territorial del Instituto Nacional de Estadística, Geografía e Informática (1979) se registra que Mesa de Tijuana fue integrada por conurbación a la ciudad de Tijuana. Por lo tanto, en el censo de 1980 esa localidad no aparece, ya que su población es contabilizada como parte de la ciudad de Tijuana. Esto explica que en los censos de 1970 y 1980 se asignaron a Tijuana espacios diferentes, lo que afectó la comparación intercensal. Por consiguiente, si queremos realizar un análisis válido del crecimiento poblacional en las áreas rurales y urbanas del municipio entre los años 1960 y 1980 , es conveniente sumar en 1970 la población de Mesa de Tijuana a la de la cabecera del municipio. Esto conlleva cambios importantes en las tasas medias anuales de crecimiento total y social de la Ciudad de Tijuana y del área rural del municipio.

Las implicaciones derivadas de este ajuste serían:

a) La ciudad de Tijuana habría crecido entre 1960 y 1970 a tasas más elevadas y entre 1970 y 1980 a tasas notablemente más bajas que las que aparecen en los cuadros 1 y 2 . En efecto, entre

población rural, cuya causa ignoramos. En efecto, esta población se triplica entre 1950 y 1960 para reducirse notablemente en 1970 y volver a aumentar en el último decenio. 
1960 y 1970 la tasa media de crecimiento de la población habría sido de $8.23 \%$ anual y la tasa media de crecimiento social de $4.83 \%$ anual. Entre 1970 y 1980 estas tasas serían: la de crecimiento total de $2.66 \%$ anual (en lugar de $4.23 \%$ que aparece en los cuadros 1 y 2), y la de crecimiento social de $-0.64 \%$ anual (en lugar de $1.02 \%$ que se observa en el cuadro 2). Como se puede apreciar, con estos ajustes la ciudad de Tijuana pasaría a registrar, al igual que otras ciudades fronterizas, un crecimiento social negativo en el último decenio y por consiguiente, esta localidad debería ser calificada como de "débil expulsión" y no de "débil atracción" como se sugería en la nota 4.

b) El área rural registraría también cambios notables en sus tasas de crecimiento. ${ }^{7}$ Entre 1960 y 1970 tales tasas pasan a ser para el crecimiento total de $-0.10 \%$ y el social de $-3.5 \%$. Para 1970 1980 tales tasas serían de $8.88 \%$ medio anual para el crecimiento total y de $5.58 \%$ para el crecimiento social. El volumen absoluto de la población rural pasaría, con el ajuste efectuado, de 13316 habitantes en 1960 a 13183 en 1970, para ascender en 1980 a 31757 habjtantes. Debemos señalar que este último monto podría estar encubriendo otros fenómenos de conurbación, aunque de menor importancia que el que hemos destacado para el caso de Mesa de Tijuana.

\section{NUEVOS PATRONES DE CRECIMIENTO SOCIAL EN LA FroNTERA NORTE DURANTE EL PERIODO 1970-1980}

La fuerte desaceleración en el ritmo del crecimiento social en el decenio 1970-1980 constituye un fenómeno trascendente que altera los ritmos de poblamiento en las ciudades y municipios fronterizos y contradice las expectativas que existían acerca del tamaño de las principales ciudades de la frontera. ${ }^{8}$ Este cambio es consecuente con

7 Cabc señalar que, aunque estamos llamando "rural" a la población que surge de restar al total del municipio los habitantes de la ciudad principal, es factible que en algunos casos esto no sea totalmente apegado a la realidad, aunque resulta estad ísticamente correcto si se considera como rural a toda localidad menos de 15000 habitantes (véase al respecto L. Unikel, et al., El desarrollo Urbano de México, El Colegio de México, México, 1982, pp. 337-353).

8 Como ejemplo de expectativas demasiado elevadas en torno a la población que alcanzarian las ciudades fronterizas para 1980, véase a Peter Baird y Ed. Mc Caughan, México-Estados Unidos: relaciones económicas y lucha de clases, Era, México, 1982, p. 215. Se mencionan en ese libro las siguientes estimaciones de población para las principales ciudades fronterizas en 1980: Tijuana, 566 000; Mexicali, 478 000; Ciudad Juárez, 667 000; Nuevo Laredo, 
el descenso que se viene observando desde 1950 en las tasas de crecimiento social; sin embargo, tal descenso no afectó entre 1950 y 1960 el volumen de la migración neta, que continuaba en ascenso, ya que las tasas menores derivaban de una población base cada vez más elevada. Entre 1960 y 1970 se produjo en algunas de las principales ciudades fronterizas un nuevo fenómeno: el descenso en las tasas de crecimiento social vino acompañado de un descenso en el volumen absoluto de la migración neta incorporada durante dicho periodo en Matamoros, Ciudad Juárez, Mexicali y Tijuana. ${ }^{9}$ Entre 1970 y 1980 este fenómeno se generaliza y abarca a todas las localidades fronterizas importantes: al fuerte descenso en las tasas anuales de crecimiento social le acompaña un descenso significativo en el monto -en números absolutos-- de la migración neta. En este último decenio se observa un crecimiento social negativo de cierta importancia en las ciudades de Nuevo Laredo, Matamoros y Mexicali.

Los cambios que estamos señalando en las tendencias del crecimiento social en la franja fronteriza norte. nos sugieren las siguientes consideraciones:

a) A pesar de la casi desaparición del crecimiento social, la población de la franja fronteriza ha seguido aumentando en el último decenio como consecuencia del aún importante crecimiento natural. Sin embargo es ya notorio un descenso significativo en los niveles estimados de natalidad: baste señalar que mientras que en 1970 la tasa bruta de natalidad era de 44.3 por mil, hacia 1979 esta misma tasa se habia reducido a aproximadamente 31.2 por mil, mientras que la mortalidad, experimentó una reducción mucho menor, pasando

238000 ; Reynosa, 347000 ; y Matamoros, 229000 . Véase también L. Unikel, et al., op. cit., cuadro IX-9, pp. 300-301, donde se exponen proyecciones de población para las ciudades más importantes. Las estimaciones más bajas que surgen de ese cuadro para las ciudades fronterizas en 1980 son las siguientes: Reynosa, 239 979; Nuevo Laredo, 272 420; Matamoros, 257 968; Mexicali, $494599 ; \mathrm{y}$, Tijuana, 542153.

9 Un cálculo aproximado del saldo neto migratorio, basado en las estimaciones de crecimiento social antes presentadas, permite destacar la fuerte intensidad del descenso registrado entre 1960 y 1970 en el volumen neto migratorio en Matamoros y Mexicali, mientras que en Tijuana y Ciudad Juárez, si bien existe una baja en números absolutos en cuanto a la población migrante incorporada en dicho periodo, el volumen se mantiene en un orden cercano al registrado en el decenio anterior. En Mexicali, que había tenido entre 1950 y 1960 la tasa más elevada de crecimiento social entre las ciudades importantes, el volumen incorporado entre 1960 y 1970 se redujo 9 veces con respecto al decenio anterior, mientras que en Matamoros el descenso fue de tres veces respecto del volumen observado previamente. 
de 8.3 por mil a 7.1 por mil en el mismo periodo, y estos comportamientos, a nivel nacional, registraron tendencias similares. ${ }^{10} \mathrm{De}$ manera que si se tiene en cuenta esta reducción en el crecimiento natural que se espera que continuará en las próximas décadas, sería razonable suponer, con base en la proyección de las tendencias señaladas, que la población en la zona se incrementará en los próximos años a un ritmo aún menos intenso que el observado en el último decenio. Pero también podría caber la tentación de extrapolar hacia el futuro las tendencias experimentadas en el crecimiento social. Sin embargo, hay que tener en cuenta que la frontera presenta peculiaridades en su vida económica que hacen más difícil que en otras regiones del país efectuar predicciones en torno al comportamiento futuro del crecimiento social; es notoria, por ejemplo, la susceptibilidad de las actividades económicas hacia las fluctuaciones y crisis que tienen lugar en Estados Unidos.

El predominio creciente de las actividades que hemos denominado "fronterizas"11 torna aún más dependiente a la economía y a la población con respecto a las condiciones imperantes en el plano internacional. En el decenio último E.U.A. ha registrado las crisis económicas más importante desde la última guerra mundial: 1970$1971,1973-1975$ y el final de la década ${ }^{12}$ señalan periodos depresivos en la economía del país vecino. Las devaluaciones del peso en 1982 y la sobrevaluación actual del dólar, consecuencia de las politicas mexicanas para superar la crisis financiera actual, han producido en la frontera cambios más intensos que en el resto del país, generando, junto con un auge comercial en el lado mexicano, un incremento

10 A nivel nacional la tasa bruta de natalidad pasó de $\mathbf{4 4 . 2}$ por mil en 1970 a 34 por mil en 1979 . En el mismo periodo la mortalidad disminuyó de 10.1 por mil a 8 por mil. Véase CONAPO, México demográfico, México, 1982, pp. 26 y 27; y, también IMSS, Fecundidad y uso de métodos anticonceptivos y atención materna en la zona fronteriza México-Estados Unidos, México, 1981, p. 3. En páginas posteriores abundaremos acerca de los niveles de crecimiento natural y sustentaremos los supuestos en que se apoyan nuestras estimaciones acerca del crecimiento social.

11 En nuestra investigación hemos llamado "fronterizas" a aquellas actividades dependientes de su localización en zonas cercanas al límite, y por ende sujetas a un riesgo mayor, ya que están expuestas a factores adicionales de desequilibrio, relacionadas con políticas del vecino país, con mercados cambiarios y con los ciclos económicos de las dos naciones. Véase, Mario Margulis "Crecimiento y migración en una ciudad de frontera: estudio preliminar de Reynosa", en R. González S. (comp.), La frontera norte, El Colegio de México, México, 1981.

12 La susceptibilidad de la economía de las ciudades mexicanas de la frontera norte ante los procesos recesivos en el país vecino, se pone de ma- 
enorme en el costo de la vida, difícil de sobrellevar para la mayor parte de la población.

En conclusión, si bien es oportuno esperar una continuación en la tendencia descendente del crecimiento natural, la estimación del futuro crecimiento social plantea fuertes dificultades y no puede basarse en proyecciones derivadas de los patrones observados en el pasado. En la zona froateriza, el crecimiento social dependerá de la evolución que registre la actividad económica en la región, de los incentivos que surjan para un desarrollo económico menos dependiente y más integrado a la nación, y de la evolución que se produzca en la economía nacional, en el empleo y en los procesos de redistribución espacial de la población mexicana.

$b$ ) El fuerte descenso en el crecimiento social en ciudades y municipios fronterizos, parece tener su origen -desde un punto de vista demográfico- en los siguientes fenómenos, combinados entre sí:

1. Una disminución en la intensidad de la inmigración a la frontera, como consecuencia de una reorientación de los flujos migratorios hacia otras áreas del país o de E.U.A., y/o de una mayor retención de migrantes potenciales en las áreas de origen.

2. Un incremento en la intensidad de la emigración desde las ciudades y municipios fronterizos.

La combinación de estos dos componentes puede reflejarse en una disminución del crecimiento social. Acaso sea posible formular algunas reflexiones que vinculen estos fenómenos demográficos con ciertos procesos económicos ocurridos a lo largo del decenio; sin embargo, se requería de un estudio específico de los acontecimientos económicos de dicho periodo y de su impacto en la frontera, a la luz del hallazgo realizado acerca de la práctica desaparición del crecimiento social en el último decenio. A título de hipótesis apuntaremos, no obstante, algunas líneas que, de ser profundizadas, podrían explicar el cambio ocurrido en los fenómenos migratorios.

Parece que el dinamismo de la economía en la frontera no fue suficiente como para mantener un ritmo de crecimiento en la fuerza

nifiesto en los efectos que tuvo sobre el empleo la crisis norteamericana de 1973-1975: "en unos cuantos meses, entre octubre de 1974 y abril de 1975, se cerraron 39 plantas de ensamble de propiedad norteamericana en la región fronteriza mexicana, mientras que otras reducían hasta en $50 \%$ su fuerza de trabajo. En 1975 se despidió a más de 32000 obreros en menos de 10 meses,... Otras 70 maquiladoras desaparecieron en los primeros 5 meses de 1976. .." (P. Baird, y Ed. Mc Caugham op. cit., p. 238). 
de trabajo, similar al de las décadas anteriores. El desarrollo de esta economía en el decenio en cuestión se vinculó, sobre todo, a "actividades fronterizas" y como tales, fueron sujetas en mayor grado a las fluctuaciones derivadas del comportamiento de la economía internacional y de los ciclos económicos en los E.U.A. Las maquiladoras y el impulso al comercio local parecen haber concentrado la mayor parte de los estímulos oficiales canalizados hacia el desarrollo fronterizo. Debemos recalcar que este último fue capaz, no obstante, de aumentar la población ocupada, pero no de mantener los ritmos anteriores de absorción de la fuerza de trabajo. Por otra parte, durante el último decenio la creciente inversión pública y una parte de la actividad privada, dieron lugar, sobre todo en los años más dinámicos, al avance de otras regiones del país que fungieron como alternativas exitosas para la reorientación de flujos migratorios. Tal es el caso del desarrollo turístico (Cancún y Zihuatanejo), de la implantación de complejos siderúrgicos (Lázaro Cárdenas) y de Puertos Industriales, de la industria de la construcción favorecida por grandes obras públicas, de la enorme expansión de PEMEX y el consiguiente desarrollo de la petroquímica en diversos espacios del territorio nacional y del auge experimentado durante una parte del decenio por algunos grupos industriales; ciertas zonas del país aparecieron como nuevos espacios de absorción migratoria y pudieron competir con la frontera como lugar de atracción. Por lo tanto la reorientación de las migraciones y de la emigración desde la franja fronteriza puede haber respondido a una reducción de la dinámica económica de la frontera, aunada a la fuerte expansión de la inversión pública y privada en otras áreas del país.

\section{LA CIUDAD DE REYNOSA: CARACTERÍSTICAS DEL CRECIMIENTO POBLACIONAL}

$\mathrm{Si}$ bien este artículo se propone destacar los cambios ocurridos en el crecimiento social de las principales ciudades y municipios de la frontera norte, vamos a referirnos en los próximos párrafos con mayor detalle a la evolución poblacional de Reynosa y a las características de su desenvolvimiento demográfico. De la investigación que hemos realizado en estè municipio, surgió una información más rica y detallada que nos permitió profundizar en el análisis de los componentes del crecimiento social de Reynosa y al mismo tiempo formular hipótesis para ser exploradas en otros lugares de la frontera.

Para examinar correctamente la evolución poblaciónal de Reynosa y comparar su crecimiento con el de otros municipios 
fronterizos, es preciso tener en cuenta los cambios ocurridos en los límites del municipio. El principal de ellos se produjo en 1961, cuando se segregaron de Reynosa $2140 \mathrm{~km}^{2}$, destinados a la creación del nuevo municipio de Río Bravo. Ocho años antes, en 1953, se creó el Municipio de Valle Hermoso, sobre todo, en el territorio segregado de Matamoros, pero incluyendo también algunas localidades que pertenecían a Reynosa. Para examinar el crecimiento comparativo de los municipios, hemos partido de los límites territoriales de Reynosa y Matamoros anteriores a la segregación; para 1960, 1970 y 1980 , sumamos a la población de Matamoros, la de Valle Hermoso, y para 1970 y 1980, agregamos a Reynosa la del municipio de Río Bravo. Como las localidades segregadas de Reynosa en 1953 -incluidas en Valle Hermoso - contaban con una población muy exigua, apenas 659 habitantes en 1970, no las hemos tomado en cuenta para los análisis que siguen.

E1 crecimiento poblacional de Reynosa fue intenso a partir de 1930. En ese año, el municipio contaba con 12346 habitantes que el censo calificaba como rurales y la ciudad alcanzaba los 4840 habitantes. Para 1940, llegó a tener 23137 y 9412 habitantes, respectivamente, con un ritmo de crecimiento más elevado en el medio urbano que en el rural. Entre 1940 y 1950 el aumento se aceleró; la población del municipio se triplicó y en la ciudad se cuadruplicó. El porcentaje anual de crecimiento del municipio alcanzó $11.32 \%$ y la ciudad avanzó a una tasa media anual de $13.38 \%$. Entre 1950 y 1960 ese ritmo se redujo, aunque siguió siendo muy elevado. El municipio prácticamente duplicó su población y la ciudad excedió ese crecimiento con una tasa media anual de 8.08 por ciento. El incremento poblacional fue todavia intenso en el decenio siguiente, aunque su velocidad, algo menor. El municipio (incluyendo Río Bravo) alcanzó los 222175 habitantes y la ciudad creció a una tasa media anual de $6.61 \%$, alcanzando los 137383 habitantes. Entre 1970 y 1980 la población de la ciudad de Reynosa pasó de 137383 a 194693 habitantes, experimentando una tasa de crecimiento promedio anual de 3.43 por ciento. Los municipios de Reynosa y Río Bravo alcanzaron en conjunto una población de 292934 , con una tasa de crecimiento anual de 2.78 por ciento. Considerando por separado a ambos municipios se observa que el de Reynosa creció en el último decenio a una tasa de $3.32 \%$ anual, mientras que el municipio de Río Bravo alcanzó sólo $1.53 \%$ anual.

La ciudad de Reynosa, que durante casi dos siglos había conservado sus características de pequeña población, y vivido fundamen- 
talmente de la ganadería y agricultura facilitadas por la cercanía del río, comenzó a crecer rápidamente a partir de 1930. Este proceso es espectacular, en veinte años -para 1950- la población se había multiplicado siete veces; en cincuenta años -para 1980- la población existente en 1930 en la ciudad de Reynosa se había multiplicado cuarenta veces; en el mismo periodo la población del municipio se había multiplicado por 24. Este aumento poblacional se debe, parcialmente, al incremento en las tasas de crecimiento natural, pero el principal factor en esta zona ha sido la migración. Como se advierte en el cuadro 2, el incremento poblacional fue muy intenso durante casi todo el periodo en cuestión, como resultado de la combinación de altas tasas de crecimiento natural con importantes saldos migratorios.

Sin embargo, y al igual que en otras ciudades fronterizas (véase cuadro 2), en el último decenio, el crecimiento social descendió a niveles insignificantes $(0.13 \%$ anual), dando aparente fin a un ciclo prolongado de elevados saldos migratorios positivos. Los municipios de Reynosa y Río Bravo en su conjunto, muestran por primera vez un crecimiento social negativo, que alcánza $0.52 \%$ anual. Pero si tomamos en cuenta solamente las áreas rurales de estos municipios, excluyendo a las ciudades de Reynosa y Río Bravo, podemos apreciar que el descenso en el crecimiento social se inició en la década 19501960; en 1960-1970 el crecimiento social alcanzó ya niveles negativos importantes $(-2.81 \%$ anual), que se acentuaron entre 1970 y 1980 alcanzando $-3.46 \%$ anual (véase cuadro 3 ). Como el agrupamiento de municipios encubre ciertas diferencias entre ellos, especialmente la concentración de tierras regadas en el municipio de Río Bravo, vamos a desagregar para 1970-1980 ambos municipios para comparar el crecimiento poblacional en las respectivas áreas rurales. ${ }^{13} \mathrm{Se}$ aprecia de esta manera, el diferente comportamiento de la evolución poblacional en las áreas rurales de ambos municipios. Mientras que en Reynosa, entre 1970 y 1980 el crecimiento total fue de $2.16 \%$ anual y el crecimiento social de $-1.14 \%$, en Río Bravo se registraron tasas de crecimiento muy inferiores, $-1.29 \%$ anual de crecimiento total y $-4.59 \%$ de crecimiento social. El descenso en la población de las áreas rurales de ambos municipios, parece que se debió, por lo menos en el último decenio, a una baja notable en la población rural de Río Bravo.

13 Como Río Bravo fue segregado del municipio de Reynosa en 1961, sólo disponemos de datos a partir de 1970 para comparar ambos municipios entre sí. Para comparar periodos más largos, es obligatorio sumar ambos municipios pues de lo contrario se incurre en la falacia de comparar unidades territoriales distintas. 
La pérdida de dinamismo poblacional en las zonas rurales que estamos mencionando, parece tener su origen en las modalidades experimentadas por la producción agraria, vinculadas primero con el cambio de cultivos (sustitución del algodón por maíz y sorgo, a partir de 1950-1960) y posteriormente con la intensificación de tecnologías, ahorradoras de mano de obra. Este proceso tiene su complemento en la urbanización creciente de los dos municipios. En Reynosa la emigración de la zona rural fue anterior a la de Río Bravo -que conservó la mayor parte de las tierras de riego al producirse la separación de ambos municipios en 1961 - donde la población rural todavía alcanzaba en 1970 a 32371 personas frente a sólo 13403 en el municipio de Reynosa, es decir, $45.3 \%$ de la población total del municipio de Río Bravo frente a $8.9 \%$ en Reynosa. ${ }^{14}$ En 1980 se registraba en Río Bravo un $33.9 \%$ de población rural y en Reynosa $7.9 \%$.

En síntesis, a la pérdida casi total de dinamismo en el crecimiento social de la población urbana, registrada en el último decenio en ambos municipios, se agrega un descenso, iniciado mucho tiempo antes, en el crecimiento social de la población rural, que alcanza ya en 1960-1970 niveles negativos.

\section{El CRECIMIENTO NATURAL}

Al incorporar este tema al trabajo nos proponemos, por una parte, aproximarnos a uno de los factores básicos del crecimiento de la población en Reynosa y por otra, poner a prueba las estimaciones acerca del crecimiento social planteadas en los cuadros 2 y 3 y, por ende, la consistencia de las hipótesis que de ellos se derivan.

Para estimar el crecimiento natural de la población es necesario poder evaluar el comportamiento de la natalidad y la mortalidad. Hasta donde hemos podido investigar no existen estudios acerca de los niveles y tendencias de estos dos componentes para las ciudades de frontera. El único trabajo referente al tema con el que hemos contado y que empleamos en este artículo, es un estudio realizado por el IMSS $^{15}$ que proporciona datos acerca de la evolución del

14 La población rural evolucionó de la siguiente manera, en el municipio de Reynosa (incluyendo a Río Bravo para 1970 y 1980); 1930, 60.8 \%: 1940, $59.3 \% ; 1950,44.2 \% ; 1960,32.1 \% ; 1970,20.6 \%$ y $1980,15.3$ por ciento. Estas cifras ponen de manifiesto el intenso proceso de urbanización en la zona.

15 I.M.S.S., Fecundidad y uso de métodos anticonceptivos y atención materna en la zona fronteriza México-Estados Unidos, México, 1981. 
crecimiento natural en los estados fronterizos. Contamos también, para los municipios de Reynosa y Río Bravo, con estimaciones que hemos generado apoyándonos en estadísticas vitales.

Con la natalidad ocurrió lo contrario, ya que en los estados fronterizos bajó más intensamente que en el resto del país. Pero hay que tener en cuenta para interpretar estas tendencias que en 1940, a partir de cuando se inicia esta comparación, la mortalidad era considerablemente inferior en los estados fronterizos mientras que la natalidad superaba ampliamente a la registrada en el promedio nacional; en 1979 las diferencias en ambos casos se han vuelto mucho menores; en los estados fronterizos se registraron niveles inferiores en ambos componentes del crecimiento natural. Se puede apreciar, a partir de este cuadro, que la diferencia en las tasas de crecimiento natural en 1979 entre el país y los estados fronterizos era del orden de 0.2 por ciento. Tal diferencia surgió de tasas de crecimiento natural de aproximadamente $2.6 \%$ para el país y de $2.4 \%$ para los estados fronterizos en 1979. Es interesante señalar que en 1970 las tasas mostraban una diferencia de la misma magnitud, pero en sentido inverso: $3.6 \%$ en la zona fronteriza y $3.4 \%$ a nivel nacional. ${ }^{16}$

Dado que nuestra aproximación a la frontera, en cuanto a crecimiento natural, se ha realizado hasta aqui a partir de los estados fronterizos, que presentan características socioeconómicas generales que difieren de las propias de las ciudades limítrofes con los E.U.A., procuraremos ir hacia una mayor aproximación de nuestro objeto de estudio, tratando de evaluar el crecimiento natural en los municipios de Reynosa y Río Bravo. Para estimar la tasa bruta de natalidad hemos recurrido a los registros de nacimientos provenientes del sistema de estadísticas vitales; a fin de corregir posibles distorsiones derivadas de registros tardíos hemos extraído promedios quinquenales, cuyo resultado aparece en el cuadro 5. Las tasas así obtenidas permiten apreciar: $a$ ) una tendencia hacia el descenso en los municipios de Reynosa y Rio Bravo, en el último decenio; $b$ ) que tal tendencia es semejante a la observada a nivel nacional para el mismo periodo, y c) que para los años 1970 y 1978 las tasas obtenidas fueron inferiores en aproximadamente $7 \%$ para el primer año y $5 \%$ para el segundo, respecto de las cifras proporcionadas por el CONAPO para el promedio nacional.

16 Hay que tener en cuenta que estas tasas se refieren a años puntuales y por lo tanto difieren de las mencionadas para periodos intercensales. 
Cuadro 4. México: Evolución del crecimiento natural de la población en el país y en los estados fronterizos: 1940-1979

\begin{tabular}{ccccc}
\hline & $\begin{array}{c}\text { Tasa Bruta de Mortalidad } \\
\text { (por mil) }\end{array}$ & \multicolumn{2}{c}{$\begin{array}{c}\text { Tasa Bruta de Natalidad } \\
\text { (por mil) }\end{array}$} \\
Años & $\begin{array}{c}\text { Estados } \\
\text { Fronterizos }\end{array}$ & Nacional & $\begin{array}{c}\text { Estados } \\
\text { Fronterizos }\end{array}$ & Nacional \\
\hline 1940 & 18.8 & 23.4 & 49.3 & 44.6 \\
1950 & 12.4 & 16.1 & 45.7 & 45.6 \\
1960 & 9.4 & 11.5 & 47.0 & 46.1 \\
1970 & 8.3 & 10.1 & 44.3 & 44.2 \\
1979 & 7.1 & 8.0 & 31.2 & 34.0 \\
\hline
\end{tabular}

Fuente: Coordinación General del Sistema Nacional de Información "Manual de Estadísticas Básicas Sociodemográficas", SPP, México, 1979 y CONAPO, "México Demográfico", Breviario, 1979, Cuadro tomado de IMSS: op. cit., p. 3.

Si bien para estimar la natalidad en los municipios de Reynosa y Rio Bravo, tal como se muestra en el cuadro 5, hemos partido de las estadísticas vitales, no hemos podido hacer lo mismo para el cálculo de la mortalidad ya que las tasas brutas de mortalidad que surgen de la aplicación de estadísticas vitales, revelan que existe un fuerte subregistro. ${ }^{17}$ Por lo tanto hemos tenido que utilizar, nuevamente, los datos provenientes de los estudios efectuados por el IMSS (véase cuadro 4) para el conjunto de los estados fronterizos.

Uno de los principales resultados del cuadro 5 , es que nos permite apreciar que las tasas de crecimiento natural estimadas para los años puntuales de 1970 y 1978 no difieren mayormente entre los municipios de Reynosa y Río Bravo y el promedio nacional. En efecto, tales diferencias serian solamente de $-0.14 \%$ en 1970 y de $-0.03 \%$ para 1978 . Esto nos conduce a considerar que las estimaciones de crecimiento social que resultan de los cuadros 2 y 3 , basadas en el supuesto de que el crecimiento natural en la frontera fue, entre 1970 y 1980, similar al operado en el país, son aceptables. Por lo tanto no parece probable que, por lo menos para los municipios de Reynosa y Río Bravo, existan diferencias significativas entre las

17 Las tasas brutas de mortalidad que resultan de la utilización de las estadísticas vitales, alcanzan niveles poco verosímiles: para Reynosa y Río Bravo son inferiores a 5 defunciones por mil habitantes. 
Cuadro 5. México: Crecimiento natural de la población del país y de los estados fronterizos: 1970-1980

\begin{tabular}{|c|c|c|c|c|c|c|c|}
\hline \multirow[b]{2}{*}{ Años } & \multicolumn{2}{|c|}{$\begin{array}{l}\text { Tasa bruta de natalidad } \\
\text { (por mil) }\end{array}$} & \multicolumn{2}{|c|}{$\begin{array}{l}\text { Tasa bruta de mortalidad } \\
\text { (por mil) }\end{array}$} & \multicolumn{2}{|c|}{$\begin{array}{c}\text { Tasa de crecimiento } \\
\text { natural }\end{array}$} & \multirow{2}{*}{$\begin{array}{l}\text { Diferencia } \\
\text { en la tasa de } \\
\text { crecimiento } \\
\text { natural }\end{array}$} \\
\hline & Reynosa y Río Bravo & Nacional $^{2}$ & Fronterizos & Nacional $^{2}$ & Rlo Bravo & Nacional & \\
\hline 1970 & 41.0 & 44.2 & 8.3 & 10.1 & 3.27 & 3.41 & -0.14 \\
\hline 1978 & 36.0 & 38.0 & $7.1^{4}$ & 8.5 & 2.92 & 2.95 & -0.03 \\
\hline
\end{tabular}

Fuente: Estadisticas vitales, 1970-1978, Dirección General de Estadística (columna de la nota 1), Consejo Nacional de Población, México Demogréfico; Breviario de 1979, pp. $26-27$ (columnas de la nota 2), IMSS, Fecundidad y uso dẹ métodos anticonceptivos y aten-

ción materna en la zona fronteriza México-Estados Unidos, op. cit., p..3 (columna de la nota 3 ).
4 Este dato corresponde a 1979. 
tasas nacionales de crecimiento natural y las registradas en esos municipios. Claro está que nuestra estimación de la mortalidad puede ser objetada, ya que hemos partido de una evaluación correspondiente al total de los estados fronterizos. Pero aun si la mortalidad en los municipios de Reynosa y Río Bravo variase $15 \%$ en uno u otro sentido, con respecto a la estimada para los estados fronterizos, el crecimiento natural de estos municipios sólo se alejaría de la tasa promedio nacional de 1978 en $-0.08 \%$ o en $+0.14 \%$, según la dirección en que se variara la mortalidad.

\section{EL CRECIMIENTO SOCIAL}

Ya hemos descrito las tendencias generales observadas en la ciudad y municipio de Reynosa en lo que se refiere a la evolución de la población total y al crecimiento natural. Nos ocuparemos ahora de algunos aspectos del crecimiento social, examinado desde una perspectiva evolutiva.

En la ciudad de Reynosa - -según se aprecia en los cuadros 1 y 2- hubo elevados niveles de crecimiento social durante la mayor parte del periodo 1930-1980. Las tasas anuales fueron de 5.46\% entre 1930 y 1940 , y se elevaron a $10.69 \%$ en el decenio siguiente, en el que se registraron las más altas tasas de crecimiento social en las principales ciudades de la frontera. A partir de 1950 las tasas descendieron, pero hay que tener en cuenta que dichas tasas se refieren a poblaciones base cada vez mayores, elevadas por los fuertes saldos migratorios y por el progresivo impacto del crecimiento natural. Entre 1950 y 1960 la tasa media de crecimiento social, aunque reducida a $5 \%$ anual -la mitad de la vigente en el decenio anterior- era aún muy elevada. Para 1960-1970, esa tasa se.reduce a $3.21 \%$ anual, con lo que -sumado a un crecimiento natural medio de $3.4 \%$ anual en dicho periodo- el crecimiento total seguía mostrando un fuerte dinamismo. Pero entre 1970 y 1980 el crecimiento social en la ciudad de Reynosa disminuyó casi totalmente, alcanzando sólo $0.13 \%$ anual.

Un cálculo de los saldos migratorios netos en números absolutos basado en las estimaciones efectuadas con respecto a las tasas de crecimiento social (cuadros 1 y 2), permite ofrecer otra perspectiva de la evolución del aporte migratorio en la ciudad de Reynosa : entre 1930 y 1940 el saldo migratorio neto fue de aproximadamente 3000 personas; en 1940-1950 de unas 17000; en 1950-1960 de 21 500; en 19601970 de 26500 y en 1970-1980 de alrededor de 2000 . No obstante 
la declinación de las tasas a partir de 1950, se puede observar que, en números absolutos, el saldo migratorio continuó creciendo en forma ininterrumpida hasta 1960-1970, y que cayó bruscamente en la década siguiente.

En el municipio de Reynosa ${ }^{18}$ se observan tendencias similares, aunque el crecimiento social ha sido en todo momento más reducido que en la ciudad, como consecuencia -según hemos analizado en páginas anteriores- de la fuerte reducción de los saldos migratorios netos en el área rural, a partir de 1950 (véase cuadro 3).

\section{Evolución DE LA INMigRación EN REynOSA Y Rfo BRavo}

El crecimiento social es producto de la interacción de sus dos componentes básicos: la inmigración y la emigración, lo que puede dar lugar a saldos netos positivos o negativos. En este apartado procuraremos formular algunas hipótesis acerca del comportamiento de dichos componentes, poniendo especial énfasis en el cambio notable registrado en el último decenio en la dinámica del crecimiento social.

Para aproximarnos a un análisis de la evolución de los saldos migratorios netos en la ciudad de Reynosa, contamos -además de lo ya expuesto en apartados anteriores, con base en datos censalescon los resultados de la encuesta realizada en esa ciudad en octubrenoviembre de 1980 . Esta fuente nos suministró información acerca de la inmigración neta sobreviviente por periodos de llegada. Se trata de población nacida fuera de la ciudad de Reynosa, que en el momento de la encuesta residía en esta localidad. El volumen de la población sobreviviente por cohortes de llegada nos da algunos indicios acerca de la intensidad de la afluencia migratoria en diferentes momentos del tiempo; esta población ha sido mermada por dos procesos: la emigración y la mortalidad. Por lo tanto, el mayor tiempo transcurrido con respecto a su llegada a Reynosa indica --en principio- una exposición superior al riesgo de emigrar o morir. En consecuencia es lícito suponer que las cohortes más antiguas han sido las más afectadas por esos dos procesos.

Si nos atenemos a los datos de la encuesta (ciudad de Reynosa 1980) referidos a las cohortes decenales de llegada de inmigración neta sobreviviente, observamos que:

a) La inmigración alcanzó -durante casi todo el periodo- proporciones importantes con respecto a la población total (1930-1980).

18 Incluyendo el municipio de Río Bravo, a partir de 1961. 
b) La inmigración neta fue creciendo en términos absolutos a lo largo del periodo 1930-80; esto lo encontramos al comparar los sucesivos periodos decenales y surge de los datos de la encuesta con respecto a cada cohorte, retrotraídos -mediante una corrección por mortalidad - al punto medio de cada periodo intercensal.

c) Pero en términos relativos, es decir, comparando cada cohorte con la población media de cada periodo, se observa una tendencia descendente. Así, la inmigración llegada a la ciudad de Reynosa entre 1950 y 1960 , alcanzó casi $49 \%$ de la población media; para 1960 1970 la participación de la inmigración neta del periodo descendió a $24 \%$; y para el último decenio, la cohorte de llegada 1970-1980 alcanzó sólo $20 \%$ de la población media.

La fuerte inmigración observada a lo largo de los últimos decenios representó una proporción muy importante de la población residente. Según nuestra encuesta, la población de la ciudad de Reynosa en 1980 estaba compuesta por aproximadamente $53 \%$ de nativos y $47 \%$ de inmigrantes. Los datos censales que corresponden a los municipios de Reynosa y Río Bravo, en los que se considera como "migrantes" a los nacidos fuera de la entidad (no se toma en cuenta a los inmigrados desde el interior de Tamaulipas), indican que en 1950, 59 de cada 100 habitantes eran inmigrantes; hacia 1960 esta proporción se redujo a 49 de cada 100; para 1970 los inmigrantes alcanzaban $31 \%$ y 34 para 1980.19 Consideramos que es muy importante el aumento que se observó en la proporción de inmigrantes entre 1970 y 1980 , el cual se registra asimismo, si se analiza exclusivamente el municipio de Reynosa, y en el próximo apartado aventuraremos una explicación al respecto.

\section{LA CAfDA DEL CRECIMIENTO SOCIAL EN REYNOSA Y RÍo BRAVO EN EL ÚlTIMO DECENIO: LA EMIGRACIÓN}

Un análisis general, nos permite considerar que la información que surge de la encuesta, respecto de las magnitudes de cada cohorte de llegada, es consistente con nuestras estimaciones de los saldos netos migratorios, derivadas de fuentes censales y basadas en las tasas de crecimiento social. En relación con ello hemos constatado que entre 1930 y i 970 los volúmenes de inmigración neta por cohortes decenales, surgidos de la encuesta y corregidos por mortalidad, coinciden

19 En el municipio de Reynosa se registró para 1970 una proporción de migrantes de $33 \%$ y para 1980 de casi $35 \%$. 
con bastante aproximación con los saldos netos migratorios, derivados de la aplicación de las tasas de crecimiento social para cada periodo intercensal. Tal coincidencia indicaría que hasta 1970 no se habrían producido movimientos emigratorios de importancia en la ciudad de Reynosa.

Pero para el periodo $1970-1980$, los datos combinados de censos $y$ encuestas parecen indicar en forma fehaciente la existencia de una fuerte emigración, que tiende a contrarrestar -en términos de crecimiento social- con el volumen importante de inmigrantes llegados durante dicho periodo.

En efecto, mientras que nuestra estimación del saldo neto migratorio con base en datos censales da como resultado un saldo positivo de aproximadamente 2000 personas, ${ }^{20}$ la encuesta revela que en 1980 había en la ciudad de Reynosa más de 32000 personas nacidas fuera de esa ciudad, que habían arribado entre 1970 y 1980. La fuerte diferencia entre ambas cifras parece poner en evidencia una tendencia emigratoria que acaso explique - por lo menos para esta ciudad- la decadencia del crecimiento social observada durante el último decenio en Reynosa. Consideramos que el descubrimiento de una corriente emigratoria de significación constituye un hallazgo importante, porque permite descifrar parcialmente la mecánica del abatimiento del crecimiento social reciente y destaca la complejidad en el juego de flujos migratorios en la frontera. También pone de manifiesto la importancia de estudios de caso - como el presentepara formular hipótesis que hagan posible profundizar en el conocimiento de la dinámica poblacional.

Al proponer, a título de hipótesis, la existencia de una emigración de cierta significación en la ciudad de Reynosa entre 1970 y 1980, no hemos dejado de tomar en cuenta las limitaciones que surgen de la utilización de fuentes diferentes y los márgenes de error a que están sujetas las cifras que emanan de tasas de crecimiento natural y social estimadas y de una encuesta derivada de una muestra probabilística. Pero aún considerando márgenes razonables de error, la magnitud de la población faltante es tal que la hipótesis se sostiene. Para demostrarlo hemos realizado un ejercicio que consiste en hacer variar los dos elementos principales que la sustentan: las tasas de crecimiento natural en el periodo intercensal y el monto de

20 La aplicación de la tasa de crecimiento social de $0.13 \%$ anual (véanse cuadros 1 y 2) da como resultado un crecimiento social aproximado de 2000 . La cohorte de llegada 1970-1980, según la encuesta, incluye a 32000 personas. 
la inmigración neta entre 1970 y 1980.21 Hemos puesto a prueba la incidencia de estos dos factores porque sería posible argumentar que, por una parte, la elección para Reynosa de la tasa de crecimiento natural correspondiente al promedio nacional podría estar subestimado - por consecuencia- el crecimiento social, y también porque el monto de inmigración neta surgido de la encuesta se basa en una muestra que puede dar lugar a un cierto margen de error. Por lo tanto hemos realizado un análisis en el que hemos hecho variar la magnitud de esos factores a fin de observar los cambios que experimenta el volumen de la posible emigración. Esta prueba permitió verificar que aún considerando tasas promedio de crecimiento natural de $2.9 \%$ anual para el periodo $1970-1980$ y la eventualidad de que la cohorte de llegada correspondiente a ese decenio - captada por la encuesta- se redujese a la mitad, seguiría existiendo un faltante en la población final, lo que presumiblemente debiera atribuirse a la emigración. 22

No es nuestro propósito anunciar el monto exacto que pudo alcanzar la emigración entre 1970 y 1980, sino establecer su existencia y su probable importancia. Con base en las evaluaciones. pruebas realizadas y datos disponibles, estimamos que la magnitud de esa emigración se sitúa en un rango de entre 25000 y 35000 personas.

Cabe advertir que esta estimación de la emigración se refiere a las personas que estaban en Reynosa en 1970 y a sus descendientes; no incluye a la posible emigración llegada en el siguiente decenio. La cohorte 1970-1980 que hemos dicho supera a las 32000 personas según nuestra encuesta, y se refiere a las personas que llegaron en ese periodo y que al momento de la encuesta permanecían en Reynosa. Se trata de una inmigración neta y por tanto cabe la posibilidad de que una parte de ella hubiera emigrado con anterioridad al levantamiento de la encuesta. Esta consideración es relevante pues indica que la emigración total pudo haber sido superior durante el periodo que estamos tratando, y también que en periodos decenales anteriores quizá hubo emigraciones cuyo volumen no podemos evaluar, y que

21 Por inmigración neta entendemos aquí y en las páginas que siguen, a la población que inmigró entre 1970 y 1980 , reducida por la incidencia de la mortalidad y por la emigración.

22 Sin embargo, tales supuestos extremos (la baja tasa de crecimiento natural y la reducción drástica de los inmigrantes arribados durante el periodo, captados en 1980). no se justifican, ya que no existc ningún indicio para suponer un crecimiento natural medio anual inferior a $3.1 \%$ y por otra parte, los datos que surgen de la muestra, respecto del volumen de la población inmigrante residente en Reynosa, son conf irmados por los censos. 
no alcanzaron a afectar el elevado crecimiento social, vigente hasta 1970.

En páginas anteriores, al referirnos al fuerte descenso en el crecimiento social observado en la zona fronteriza en el último decenio, señalamos que éste puede haber tenido su origen tanto en la reducción de la inmigración - por retención en sus lugares de origen o por desviación de los flujos hacia otras zonas de destino-, como en la emigración.

En el caso de Reynosa, parece probable que, a la luz de nuestras estimaciones, la emigración haya sido el factor más importante para explicar el abatimiento en el crecimiento social, ya que no se observa una disminución categórica en números absolutos en la afluencia de inmigrantes, sino que, junto con una inmigración voluminosa, existió en el decenio un proceso de salida de personas hacia otros destinos.

Tal emigración puede haber tenido destinos diferentes $\mathrm{y}$ vinculación con fenómenos migratorios de naturaleza distinta. Consideramos probable que una parte importante de la emigración se haya dirigido hacia diversos puntos del pais, como consecuencia del impulso registrado en otras zonas - algunas de ellas cercanas- a partir de fuertes inversiones a lo largo del decenio anterior. No nos es posible evaluar la importancia de los E.U.A. como lugar de destino de esa emigración, pero podemos apuntar que las crisis económicas que afectaron a ese país en diferentes momentos de la década pasada, pudieron desalentar a la emigración permanente.

En lo que se refiere a la naturaleza de los procesos emigratorios, es interesante destacar que, mientras la mayor parte de la población involucrada probablemente respondió a motivaciones laborales, detectamos la existencia de otro proceso migratorio de carácter educativo, que incidió en un sector específico de la población. Se trata de la emigración, frecuente en varias ciudades fronterizas, de jóvenes - pertenecientes a estratos socioeconómicos medios o altosque se desplazan a otras ciudades del país o del extranjero, en busca de oportunidades educativas que en la mayor parte de la frontera no les son ofrecidas. Una parte de ellos no regresa, ya que la educación puede constituir el inicio de un proceso de formación profesional, cuya realización plena no encuentra las oportunidades necesarias en el espacio fronterizo.

El cuadro 6 -derivado exclusivamente de datos censales-proporciona una evidencia adicional para sostener nuestra hipótesis de la existencia de un proceso de emigración, y además pone de ma- 
Cusdro 6. Municipio de Reynosa (1950 y 1960) y suma de municipios de Reynosa y Río Bravo (1970 y 1980): población segan lugar de nacimiento

\begin{tabular}{|c|c|c|c|c|c|c|c|c|c|c|c|}
\hline \multirow[b]{2}{*}{$\begin{array}{c}\text { Lugar de } \\
\text { nacimiento }\end{array}$} & \multicolumn{2}{|c|}{1950} & \multicolumn{2}{|c|}{1960} & \multirow{2}{*}{$\begin{array}{c}\text { Tasa crec. } \\
\text { medio anual } \\
1950-1960\end{array}$} & \multicolumn{2}{|c|}{1970} & \multirow{2}{*}{$\begin{array}{c}\text { Tasa crec. } \\
\text { medio anual } \\
1960-1970\end{array}$} & \multicolumn{2}{|c|}{$1980^{2}$} & \multirow{2}{*}{$\begin{array}{l}\text { Tasa crec. } \\
\text { medio anual } \\
1970-1980\end{array}$} \\
\hline & absolutos & $\%$ & absolutos & $\%$ & & absolutos 1 & $\frac{9}{8}$ & & absolutos 1 & $\frac{q}{8}$ & \\
\hline Total & 69428 & 100.0 & 134869 & 100.0 & 6.86 & $\begin{array}{c}222175 \\
(150786)\end{array}$ & $\begin{array}{l}100.0 \\
100.0\end{array}$ & 5.30 & $\begin{array}{c}294934 \\
(2111412)\end{array}$ & $\begin{array}{l}99.2 \\
99.3\end{array}$ & $\begin{array}{l}2.78 \\
\mathbf{3 . 3 2}\end{array}$ \\
\hline $\begin{array}{l}\text { Nacidos en } \\
\text { Tamaulipas }\end{array}$ & 28707 & 41.3 & 68861 & 51.1 & 9.14 & $\begin{array}{c}152342 \\
(101460)\end{array}$ & $\begin{array}{l}68.8 \\
67.3\end{array}$ & 8.56 & $\begin{array}{c}195014 \\
(136238)\end{array}$ & $\begin{array}{l}66.1 \\
64.4\end{array}$ & $\begin{array}{l}2.42 \\
2.89\end{array}$ \\
\hline $\begin{array}{l}\text { Nacidos en } \\
\text { otra entidad } \\
\text { o en el } \\
\text { extranjero }\end{array}$ & 40721 & 58.7 & 66008 & 48.9 & 4.95 & $\begin{array}{c}69833 \\
(49326)\end{array}$ & $\begin{array}{l}31.3 \\
32.7\end{array}$ & 0.58 & $\begin{array}{c}97727 \\
(73653)\end{array}$ & $\begin{array}{l}33.1 \\
34.9\end{array}$ & $\begin{array}{l}3.30 \\
3.96\end{array}$ \\
\hline
\end{tabular}


nifiesto la importante presencia de los "nativos" en ese proceso. ${ }^{23}$ Se advierte en ese cuadro que entre 1970 y 1980 descendió, por primera vez desde 1950 , la proporción de "nativos" en la población total, mientras que la participación de migrantes aumentó, también por primera vez. Este aumento en la proporción de "no nativos" llama la atención, teniendo en cuenta la casi abolición, durante dicho periodo, del crecimiento social, e insinúa en principio, la posibilidad de una emigración significativa de "nativos".

Si como ejercicio para analizar los cuadros 6 y 7 partimos del supuesto de ausencia de inmigración y emigración durante el periodo 1970-1980, se puede demostrar que en tal caso la tasa de crecimiento medio anual de la población "nativa" debería ser muy superior a la tasa de crecimiento natural de la población total del municipio respectivo y también superar notablemente a la tasa de crecimiento medio anual de la población "no nativa". Para fundamentar esta afirmación vamos a examinar a continuación los componentes del crecimiento demográfico de cada una de estas poblaciones ("nativa", "no nativa" y total).

$A$. La población nativa residente en el municipio a principios de 1970 derivaría su crecimiento de la diferencia entre: a) el total de los nacimientos ocurridos en el municipio entre 1970 y 1980 , considerando tanto a los hijos de los "nativos" de la entidad como a los hijos de los "no nativos", y $b$ ) las defunciones ocurridas en el municipio -durante el periodo indicado- de personas "nativas", es decir, las muertes de los "nativos" residentes en el municipio en 1970, más las muertes de aquellos nacidos en el municipio durante el periodo. En síntesis, los nativos de la entidad residentes en el municipio crecerían -en ausencia de inmigración y emigración- con base en el total de nacimientos del periodo (de padres nativos y migrantes), a los que habría que deducir sólo una parte de las defunciones registradas: aquellas que afectaron a los nativos.

$B$. Los no nativos experimentarían una pérdida de efectivos, ya que el volumen de esta población existente al principio del periodo se vería reducido por las muertes, ocurridas entre 1970 y 1980 , de algunos de sus integrantes. Este conjunto no podría incrementarse

23 I.n los cuadros 6 y 7, "nativos" se refiere a los nacidos en el estado y no cxclusivamente en el municipio. En los razonamientos que siguen, vinculados a estos cuadros, se entenderá por "migrantes" o "no nativos" a los nacidos en el país o el extranjero, pero fuera de los límites de la entidad de referencia; en consecuencia, no se llamará "migrantes" a los provenientes de otros municipios de la misma entidad. 
Cuadro 7. México: Población de los principales municipios fronterizos (con excepción de Reynosa) o anual: $1970-1980$

\begin{tabular}{|c|c|c|c|c|c|c|c|c|c|c|c|c|}
\hline \multirow{3}{*}{$\begin{array}{l}\text { Nugar de } \\
\text { Nacimiento }\end{array}$} & \multicolumn{3}{|c|}{ NUEVO LAREDO } & \multicolumn{3}{|c|}{ MATAMOROS } & \multicolumn{3}{|c|}{ MEXICALI } & \multicolumn{3}{|c|}{ TIJUANA } \\
\hline & \multicolumn{2}{|c|}{ años } & \multirow{2}{*}{$\begin{array}{c}\frac{8}{b} \\
\text { Tasa } \\
\text { del 1 } \\
\text { Crec. }\end{array}$} & \multicolumn{2}{|c|}{ años } & \multirow{2}{*}{$\begin{array}{c}\frac{q}{\%} \\
\text { Tasa } \\
\text { del }{ }^{2} \\
\text { Crec. }\end{array}$} & & \multirow{2}{*}{$\begin{array}{c}\stackrel{q}{6} \\
\text { Tasa } \\
\text { del }^{1} \\
\text { Crec. }\end{array}$} & & \multirow{2}{*}{$\begin{array}{c}\$ \\
\text { Tasa } \\
\text { del } 1 \\
\text { Crec }\end{array}$} \\
\hline & 1970 & 1980 & & 1970 & 1980 & & 1970 & 1980 & & 1970 & 1980 & \\
\hline Total & 151253 & 203286 & 2.90 & 185146 & 238840 & 2.44 & 396324 & 510664 & 2.45 & 340583 & 461257 & 2.78 \\
\hline $\begin{array}{l}\text { Nacidos en } \\
\text { la entidad }\end{array}$ & 96473 & 119917 & 2.12 & 142276 & 174908 & 1.95 & 255647 & 307341 & 1.79 & 171427 & 211575 & 2.06 \\
\hline $\begin{array}{l}\text { Nacidos en } \\
\text { otra entidad } \\
\text { o en el } \\
\text { extranjero }\end{array}$ & 54780 & 82566 & 3.93 & 43870 & 61963 & 3.39 & 140677 & 198478 & 3.39 & 169156 & 244874 & 3.65 \\
\hline $\begin{array}{l}\text { No especi- } \\
\text { ficados }\end{array}$ & & 1803 & & & 1979 & & & 4845 & & & 4808 & \\
\hline
\end{tabular}


Cuadro 7. México: Población de los principales municipios fronterizos (con excepción de Reynosa) según lugar de nacimiento y tasas de crecimiento anual: 1970-1980

\begin{tabular}{|c|c|c|c|c|c|c|c|c|c|}
\hline \multirow{3}{*}{$\begin{array}{l}\text { Lugar de } \\
\text { Nacimiento }\end{array}$} & \multicolumn{3}{|c|}{ PIEDRAS NEGRAS } & \multicolumn{3}{|c|}{ ACUÑ A } & \multicolumn{3}{|c|}{ JUAREZ } \\
\hline & \multicolumn{2}{|c|}{ años } & \multirow{2}{*}{$\begin{array}{l}\text { Tasa } \\
\text { Tasa } \\
\text { del }{ }^{1} \\
\text { Crec. }\end{array}$} & \multicolumn{2}{|c|}{ años } & \multirow{2}{*}{$\begin{array}{c}\stackrel{\%}{0} \\
\text { Tasa } \\
\text { del }^{1} \\
\text { Crec. }\end{array}$} & \multicolumn{2}{|c|}{ años } & \multirow{2}{*}{$\begin{array}{c}\% \\
\text { Tasa } \\
\text { del }{ }^{1} \\
\text { Crec. }\end{array}$} \\
\hline & 1970 & 1980 & & 1970 & 1980 & & 1970 & 1980 & \\
\hline Total & 46689 & 80290 & 5.39 & 32500 & 41948 & 2.50 & 474135 & 567365 & 2.83 \\
\hline $\begin{array}{l}\text { Nacidos en } \\
\text { la entidad }\end{array}$ & 40049 & 65180 & 4.83 & 26100 & 33022 & 2.30 & 316594 & 403632 & 2.36 \\
\hline $\begin{array}{l}\text { Nacidos en } \\
\text { otra entidad } \\
\text { o en el } \\
\text { extranjero }\end{array}$ & 6649 & 14592 & 7.90 & 6400 & 8683 & 2.99 & 107541 & 157987 & 3.76 \\
\hline $\begin{array}{l}\text { No especi- } \\
\text { ficados }\end{array}$ & & 518 & & & 243 & & & 5746 & \\
\hline
\end{tabular}

Fuente: Censos Generales de Población 1970 y 1980, Dirección General de Estad ística.

1 Tasa de crecimiento medio anual.
2 Algunos autores han cuestionado las cifras de 1970 para Piedras Negras, Luis Unikel y otros, op. cit., p. 301,

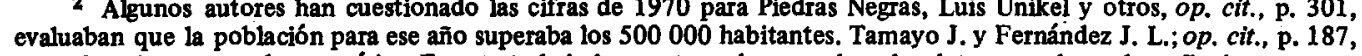
nota $d$, se hacen eco de esa crítica. En este trabajo hemos tomado como base los datos censales, cabe reflexionar acerca de las $d$ ses an do las datos del censo de 1970 y

carácter excepcional en cuanto a elevadas tasas positivas de crecimiento social en el último periodo intercensal. 
por los nacimientos, ya que los hijos de inmigrantes, nacidos en el municipio durante el periodo, son "nativos".

C. La población total del municipio, se incrementaría entonces -durante el periodo indicado- en función del aumento de los "nativos", menos la reducción experimentada por los "no nativos". Ello tendría por consecuencia lo siguiente: $a$ ) en términos absolutos, la población total experimentaría un crecimiento menor que la población "nativa", dado que en ausencia de inmigración y emigración, la población "no nativa" descendería, y $b$ ) en términos relativos, la población "nativa" crecería a una tasa media anual, muy superior a la correspondiente a la población total, ya que la totalidad de los nacimientos registrados en el municipio durante el periodo, menos sólo una parte de las defunciones, incidiría sobre una población base menor.

Si suponemos que la tasa media de crecimiento anual de la población total del municipio, en ausencia de inmigración y emigración (o sea la tasa media de crecimiento natural) fue semejante a la observada a nivel nacional, que alcanzó $3.3 \%$ durante el decenio 1970-1980, la población nativa debió haber crecido, dados los supuestos que estamos empleando, a una tasa media anual muy superior.

Contemplemos ahora los efectos derivados de posibles movimientos migratorios que hubieran afectado al municipio:

a) Si hubiese habido en el municipio un saldo neto migratorio positivo proveniente del interior de la entidad, el incremento habria sido contabilizado en el rubro de "nativos", y por ende el crecimiento relativo de éstos, durante el decenio, habría sido mayor. No se altera por lo tanto, la proposición de que el crecimiento de la población nativa debería superar notablemente a la tasa media anual de crecimiento natural para el total del municipio estimada en aproximadamente $3.3 \%$.

b) Si hubiese habido un saldo neto migratorio positivo desde el exterior de la entidad, se incrementaría el número de los contabilizados como "no nativos", siempre y cuando este saldo neto fuera superior a las defunciones de "no nativos" durante el periodo. ${ }^{24}$ Sólo en esta situación puede explicarse el crecimiento de la población "no

24 Nos estamos refiriendo en este caso, exclusivamente a la diferencia entre la inmigración y la emigración de personas nacidas fuera de la entidad. El impacto que la emigración de "no nativos" pudiera eventualmente tener sobre la emigración de los "nativos" (acompañantes familiares) aparecería en el punto c): "emigración de nativos". 
nativa" observada para 1970-1980 en los cuadros 6 y 7 . Pero no se alterarían las conclusiones expresadas en los párrafos anteriores con respecto a las tasas medias a que debería haber crecido la población nativa (superiores a $3.3 \%$ anual).

c) Sólo una importante emigración de la población nativa (que fuera muy superior a la posible inmigración proveniente del interior de la entidad) puede explicar las tasas notablemente inferiores a $3.3 \%$ medio anual. ${ }^{25}$ Otra explicación a las tasas que se observan, para el periodo $1970-1980$, en los cuadros 6 y 7 no parecería ser tan conveniente. ${ }^{26}$

Un examen más detenido del cuadro 6 en lo que se refiere al municipio de Reynosa para el periodo 1970-1980, permite advertir que:

a) La población total creció a una tasa media de $3.32 \%$ anual.

b) La población "no nativa" creció a una tasa media de $3.96 \%$ anual.

c) La población "nativa" creció a una tasa media de $2.89 \%$ anual; es decir, una tasa muy inferior a la que se esperaría, en ausencia de un saldo migratorio negativo en esa población.

En consecuencia, y de acuerdo con los razonamientos que hemos efectuado, se concluye que en el municipio de Reynosa:27

- Hubo durante el periodo 1970-1980, una considerable afluencia de inmigrantes provenientes de fuera de la entidad, que redundó en un incremento de la población "no nativa" (como puede apreciarse en el inciso $b$ ).

- Se produjo una emigración de cierta importancia en ese periodo intercensal, ya que a pesar de haberse registrado un incremento en la población "no nativa", el crecimiento social en la población total del municipio fue prácticamente nulo.

25 Si la emigración no fuera importante, podría ocurrir que aún con saldo neto migratorio negativo, la población "nativa" creciera a una tasa media anual superior a $3.3 \%$.

26 Sería posible aducir que como la población nativa tiene un perfil de edades más joven, podría haberse visto disminuida por el conocido fenómeno de la subenumeración en los censos de la población del grupo de edad 0-4 años y atribuirse parcialmente a tal subenumeración el faltante de nativos que estamos destacando en el periodo 1970-1980. Sin embargo, hay que considerar que la subenumeración afecta tanto al censo del inicio como al del final del periodo $y$, por ende, aún concediendo proporciones similares de subenumeración a ambos censos, la incidencia de este fenómeno sería insignificante.

27 Lo mismo se observa, aunque con tasas diferentes, para el conjunto de los municipios de Reynosa y Río Bravo (cuadro 6). 
- En la emigración participaron los "nativos" (del municipio y estado) en forma significativa (como puede verse en el inciso $c$ ).

\section{LA CAÍDA DEL CRECIMIENTO SOCIAL EN LOS PRINCIPALES MUNICIPIOS DE LA FRONTERA: LA EMIGRACIÓN DE NATIVOS}

Estos hallazgos relativos al municipio de Reynosa (y al conjunto de los municipios de Reynosa y Río Bravo), que parecen consolidar nuestras hipótesis acerca de la emigración en el decenio 1970-1980 en la ciudad de Reynosa y permiten constatar que nuestras especulaciones acerca de la emigración de nativos tienen bases empíricas, nos llevan a explorar, a partir de datos censales, similares a los empleados para construir el cuadro 6, la situación existente en otros municipios de la frontera. Ya habíamos señalado que las tendencias hacia el abatimiento en el crecimiento total y en particular en el crecimiento social, eran comunes a las principales localidades y municipios fronterizos, pero no nos habíamos aventurado aún a generalizar las hipótesis formuladas para Reynosa acerca de la emigración, dado que solamente para esa ciudad contábamos con el auxilio de una encuesta realizada en 1980.

Como el análisis realizado a partir de la información censal, tomando como base el cuadro 6 , nos da elementos para alentar nuestras hipótesis, nos proponemos ahora investigar -con base también en los datos que suministran los censos- si es posible proponer la existencia de corrientes emigratorias de importancia en otros lugares de la frontera, $y$ asimismo, si los nativos - a nivel municipio y estadoparticiparon en esa emigración en forma significativa. En otras palabras, averiguar si en otras partes de la frontera, el abatimiento del crecimiento social responde a patrones similares a los esbozados para Reynosa, o sea: la continuación de la inmigración a los municipios, contrarrestada por corrientes de emigración en las que es visible la presencia de nativos.

Un análisis global del cuadro 7, nos permite comprobar que en los principales municipios de la frontera parecen cumplirse las hipótesis señaladas para Reynosa. En efecto, se aprecia en estos municipios (con excepción de Piedras Negras que atravesó en el decenio por una situación particular) ${ }^{28}$ que: $a$ ) ha continuado la afluencia migra-

28 En el caso de Piedras Negras la construcción de una importante planta termoeléctrica en la localidad vecina de Río Escondido, que aprovecha los grandes yacimientos carboníferos descubiertos en la zona, podría también ex- 
toria proveniente de otros estados, a pesar de que las tasas de crecimiento social fueron muy bajas o negativas; $b$ ) ello nos lleva a concluir que ha habido una corriente emigratoria de importancia, puesto que sólo así sería compatible ese crecimiento social (nulo o negativo) con el crecimiento de la población inmigrante a tasas considerables y $c$ ) se advierte la presencia de nativos - de estado y municipio- en esa emigración, ya que la población de nativos (en cada uno de los municipios analizados) ha crecido a tasas medias anuales muy inferiores a las estimadas para el crecimiento natural de la población total de cada municipio. ${ }^{29}$

La observación de que en las ciudades y municipios de la frontera ha continuado afluyendo población migrante durante el último decenio, y que esta inmigración se ha contrarrestado con un proceso emigratorio en el cual fue importante la presencia de "nativos", plantea la necesidad de investigar, desde un ángulo sociológico la naturaleza de esos procesos, cuya complejidad es evidente. Consideramos probable que la mayor parte de la población involucrada en tales migraciones, los que inmigran y los que emigran, no difiera profundamente en cuanto a su situación socioeconómica. Además, "nativos" y "no nativos" no constituyen una diferenciación sociológica tan trascendente como puede parecer a primera vista. De acuerdo con los datos que surgen del estudio de caso efectuado en Reynosa, los "nativos" y los inmigrantes recientes se caracterizan en general -desde un punto de vista laboral-por estar ocupados en tareas de baja calificación. Muchos "nativos" son -en la fronterahijos de migrantes y un gran número de hogares conjuga a "nativos" y "no nativos": por ende, no se trata de grupos sociales autónomos

plicar el diferente patrón de crecimiento demográfico observado en este municipio. Esto parece confirmarse por el hecho poco usual de que la población del municipio creció en la reciente década a una tasa anual superior a la registrada para la localidad principal (ciudad de Piedras Negras). Véase al respecto nota 2 del cuadro 7.

29 Debemos señalar que nuestras observaciones acerca de los nuevos patrones de crecimiento social, observados en las principales localidades y municipios de la frontera norte $-y$ en especial la importante corriente emigratoria en la que es notable la presencia de nativos-, derivan principalmente de los datos censales y, en particular, de la información correspondiente al Censo de 1980, que acaba de publicarse para algunas entidades federativas. Esta fuente de datos no ha sido sometida aún a una crítica que, ermita identificar eventuales errores en la información. Creemos necesario realizar una evaluación de los datos censales más recientes, con el fin de corroborar, o en su caso modificar, las hipótesis que aquí han sido planteadas. 
sino que están integrados en las mismas unidades domésticas, diferelıciándose por su posición en el parentesco; en consecuencia, las categorias "nativo" e "inmigrante" estarian reflejando con frecuencia un fenómeno generacional antes que una dicotomía social.

En algunos casos la emigración de "nativos" podría abordarse desde un enfoque familiar e intergeneracional: ${ }^{30} a$ ) una posibilidad consiste en ser hijos de "no nativos" que acompañan a sus padres en la emigración. En este caso, el fenómeno principal sería la emigración de jefes de familia, después de una estadía de duración variable, se hayan dirigido a otra ubicación llevando consigo a sus hijos nacidos durante su permanencia en el primer sitio; $b$ ) otra situación es el caso de nativos jóvenes, hijos de familias relativamente acomodadas ya asentadas en la zona, que poseen aspiraciones educacionales, laborales y de ascenso económico que no se satisfacen con las oportunidades, ofrecidas en los últimos años en la región. En estas situaciones particulares estaríamos a veces en presencia de un ciclo migratorio familiar complejo, que se inicia con la inmigración de miembros de una generación en el pasado, y culmina con la emigración de integran. tes de otra generación.

Sin embargo, es necesario destacar que consideramos que la mayor parte de los emigrantes pertenecen a grupos sociales de bajos ingresos y poca calificación laboral: algunos, "desilusionados" de la frontera, se dirigen a otros lugares del país, cuyo desarrollo fue más intenso en el decenio pasado; otros concretan el traslado hacia los Estados Unidos, ${ }^{31}$ para lo cual su estadía en las ciudades fronterizas facilita los conocimientos y contactos, que hacen menos arduo el pasaje.

Los análisis que hemos efectuado ponen de relieve la complejidad de los flujos migratorios en la zona fronteriza; en este capítulo hemos logrado evaluar los componentes contradictorios que se ocultan tras las bajas tasas de crecimiento social del último periodo intercensal.

30 Los casos que presentamos son sólo ejemplos, que no pretenden agotar la gama de posibilidades.

31 Recordemos que el censo de 1970 fue levantado en enero, época en que los migrantes temporales a E.U.A. suelen encontrarse en sus lugares de origen, mientras que el censo de 1980 fue levantado en junio, la temporada de mayor demanda de fuerza de trabajo temporal mexicana en el país vecino. $\mathrm{Si}$ bien, tratándose de un "censo de derecho", los ausentes temporalmente deben ser registrados como residentes habituales cuando su ausencia no es mayor de seis meses, es posible que alguna fracción de la "población faltante" pueda ser atribuida a un defecto en el relevantamiento censal de aquellos que temporalmente se encontraban trabajando en E.U.A. 
Si es correcta la hipótesis acerca de que los involucrados en la inmigración y la emigración son, en general, personas pertenecientes a un mismo nivel socioeconómico, queda en pie la incógnita que plantean estas migraciones cruzadas: ¿Por qué unos dejan la frontera y otros acuden a ella? 